\title{
The Kidney Awareness Registry and Education (KARE) study: protocol of a randomized controlled trial to enhance provider and patient engagement with chronic kidney disease
}

Delphine S. Tuot ${ }^{1,45^{*}}$, Alexandra Velasquez', Charles E. McCulloch ${ }^{3}$, Tanushree Banerjee ${ }^{2,4}$, Yunnuo Zhu ${ }^{2}$ Chi-yuan Hsu', Margaret Handley ${ }^{2,3}$, Dean Schillinger ${ }^{3,4}$ and Neil R. Powe ${ }^{2,4}$

\begin{abstract}
Background: Chronic kidney disease (CKD) is common and is associated with excess mortality and morbidity. Better management could slow progression of disease, prevent metabolic complications, and reduce cardiovascular outcomes. Low patient awareness of CKD and ineffective patient-provider communication can impede such efforts. We developed provider and patient-directed interventions that harness health information technology to enhance provider recognition of CKD and delivery of guideline concordant care and augment patient understanding and engagement in CKD care.

Methods/design: We report the design and protocol of the Kidney Awareness Registry and Education (KARE) Study, a 2x2 factorial randomized controlled trial that examines the impact of a multi-level intervention on health outcomes among low-income English, Spanish and Cantonese-speaking patients with CKD in a safety net system. The intervention includes: (1) implementation of a primary care electronic CKD registry that notifies practice teams of patients' CKD status and employs a patient profile and quarterly feedback to encourage provision of guideline-concordant care at point-of-care and via outreach; and (2) a language-concordant, culturally-sensitive self-management support program that consists of automated telephone modules, provision of low-literacy written patient-educational materials and telephone health coaching. The primary outcomes of the trial are changes in systolic blood pressure (BP) and the proportion of patients with BP control $(\leq 140 / 90 \mathrm{mmHg})$ after one year. Secondary outcomes include patient understanding of CKD, participation in healthy behaviors, and practice team delivery of guideline-concordant CKD care.
\end{abstract}

Discussion: Results from the KARE study will provide data on the feasibility, effectiveness, and acceptability of technology-based interventions that support primary care efforts at improving health outcomes among vulnerable patients with CKD.

Trial registration: ClinicalTrials.gov, number: NCT01530958

Keywords: Chronic kidney disease, Self-management, CKD awareness, Health coaching

\footnotetext{
*Correspondence: Delphine.tuot@ucsf.edu

'Division of Nephrology, University of California, San Francisco, San Francisco,

CA 94143, USA

${ }^{4}$ Center for Vulnerable Populations at San Francisco General Hospital, San

Francisco, CA, USA

Full list of author information is available at the end of the article
}

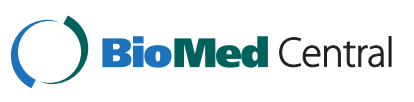

(c) 2015 Tuot et al. Open Access This article is distributed under the terms of the Creative Commons Attribution 4.0 International License (http://creativecommons.org/licenses/by/4.0/), which permits unrestricted use, distribution, and reproduction in any medium, provided you give appropriate credit to the original author(s) and the source, provide a link to the Creative Commons license, and indicate if changes were made. The Creative Commons Public Domain Dedication waiver (http://creativecommons.org/publicdomain/zero/1.0/) applies to the data made available in this article, unless otherwise stated. 


\section{Background}

Chronic kidney disease (CKD) is common, with an estimated prevalence of $11.5 \%$ among the U.S. adult population [1], causes excess mortality [2], and is associated with significant socio-demographic disparities [3, 4]. Racial/ethnic minorities and the poor, often treated in safety-net health systems, are more likely to have CKD at an earlier age [5-7]. Although randomized controlled trials have demonstrated that measures such as blood pressure control [8], reduction of proteinuria with angiotensin converting enzyme inhibitors (ACEi) or angiotensinogen receptor blockers (ARB) [9-11], and glycemic control among persons with diabetes $[12,13]$, can delay CKD decline and decrease CKD-associated morbidity and mortality [14], many individuals with CKD are not benefiting from these scientific advances. Lack of translation may be due to low levels of CKD awareness among providers and patients [15-17]; low self-efficacy among primary care providers for delivery of CKD care [18], particularly in an inefficient health care system with overburdened providers that deliver chronic disease care; and poor patient empowerment to participate in healthy lifestyles, adhere to medication regimens, and avoid nephrotoxic insults $[19,20]$.

The Chronic Care Model posits that an informed patient and prepared practice team have productive interactions that lead to improved outcomes [21]. It provides a framework for the delivery of high-quality chronic disease care and can be integrated into the Patient Centered Medical Home [22]. Implementation of single elements of the Chronic Care Model (e.g., health care organization, community resources, patient selfmanagement support, delivery system re-design, decision support) can improve processes of care, such as decreased hospitalizations among patients with congestive heart failure [23]. Interventions that have enhanced patient outcomes have incorporated several elements of the Chronic Care Model [24]. For example, data from the North Carolina Improving Performance in Practice program, a state-wide quality improvement program aimed at improving health outcomes among patients with diabetes, demonstrated a positive graded association between improved cholesterol levels among patients with diabetes and the extent to which clinical practices implemented and used the following components of the multi-level intervention: diabetes and lipid registry, list of standardized items that are addressed with every diabetic patient at every visit, comprehensive care protocols for diabetes management and patient selfmanagement support systems [25].

Sustainable multi-level interventions that enhance CKD management in primary care settings are rare, and none have been studied in U.S. safety-net delivery systems, where vulnerable populations (e.g., the poor, minorities, limited health literacy/English proficiency) bear a disproportionate burden of disease $[5,26]$ and experience large translational gaps between research and practice [27]. We describe the design and protocol of the Kidney Awareness Registry and Education (KARE) study, which assesses the effectiveness and feasibility of a multi-level intervention to improve blood pressure control among low-income patients with CKD. The intervention targets primary care practice teams and patients using multiple elements of the Chronic Care Model, including delivery system redesign, decision support, patient self-management support, organizational change and information systems. It also harnesses the core elements of a Patient Centered Medical Home, including robust data infrastructure, team-based delivery of chronic disease care and provider and patient education. The KARE intervention consists of: (1) an electronic CKD registry that provides point-of-care decision support to clinicians regarding CKD management; (2) outside-of care summaries of CKD relevant clinical data to optimize delivery of guideline-concordant CKD care by practice teams; and (3) a comprehensive patient selfmanagement support program, entitled CKD-ATSM (automated telephone self-management), that includes low-literacy educational materials; proactive, automated telephone self-management support; and live telephone health coaching (Fig. 1).

\section{Methods/design Study design}

KARE is a non-blinded $2 \times 2$ factorial randomized controlled trial with two levels of randomization. Primary care providers are randomized to one of two arms: access to an electronic CKD registry or usual care. Patients are subsequently randomized to one of two arms: CKD self-management program (CKD-ATSM) or usual care. This study design, with 4 study arms, allows assessment of the individual and additive impact of both interventions (Fig. 2). Approval to conduct this study was granted by the Committee of Human Research at the University of California, San Francisco.

\section{Study population and setting}

Patients with CKD and their providers are recruited from primary care clinics in the San Francisco Health Network, the integrated public health care delivery system serving San Francisco's uninsured and publicly insured residents. The study team collaborates with the staff at each clinic to implement and monitor the study.

\section{Eligibility criteria \\ Providers}

All primary care providers, including attending physicians, family practice and internal medicine trainees, nurse practitioners and physician assistants who provide 


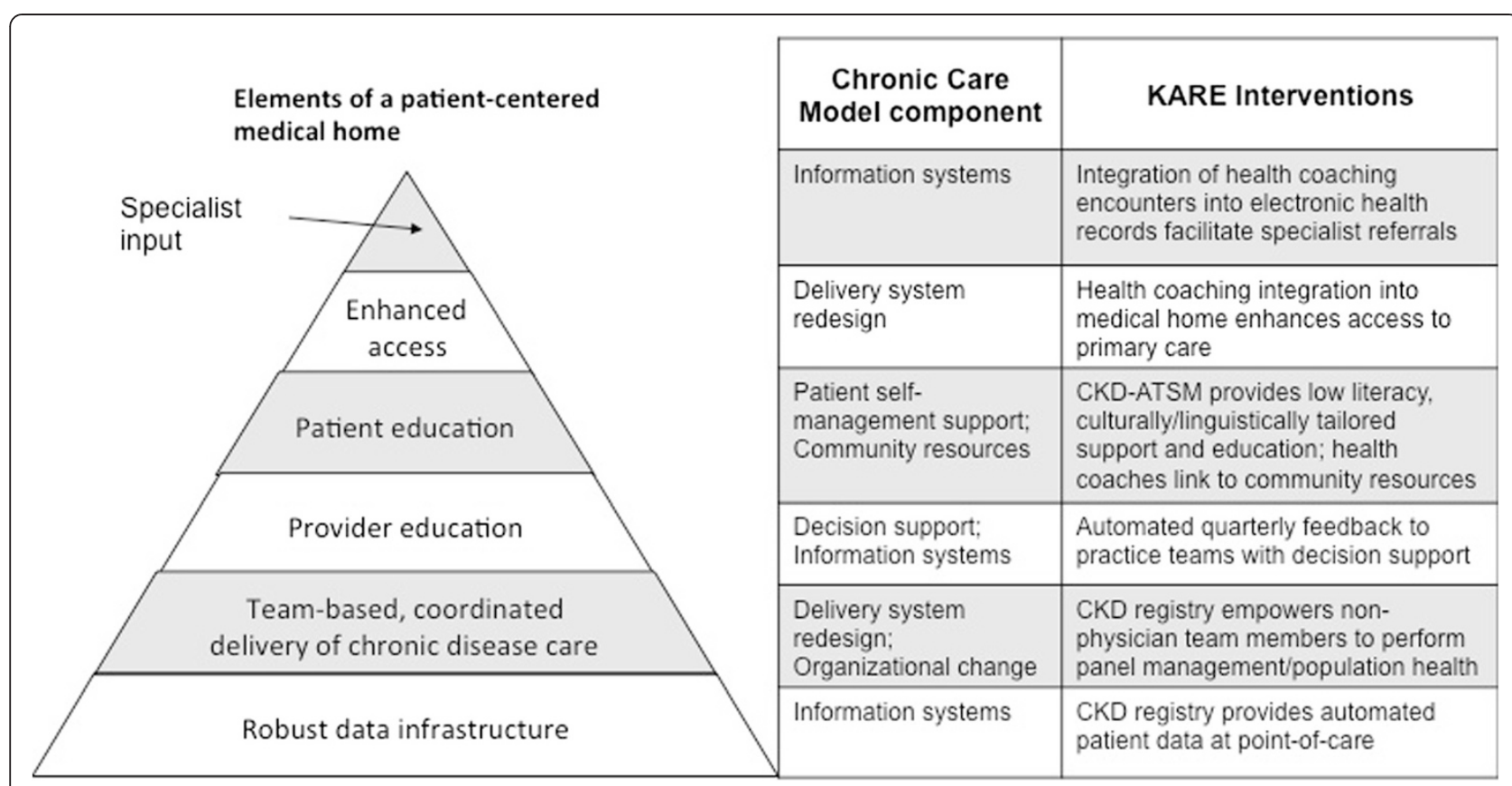

Fig. 1 KARE incorporates components of the Chronic Care Model and integrates with a patient-centered medical home to enhance health outcomes

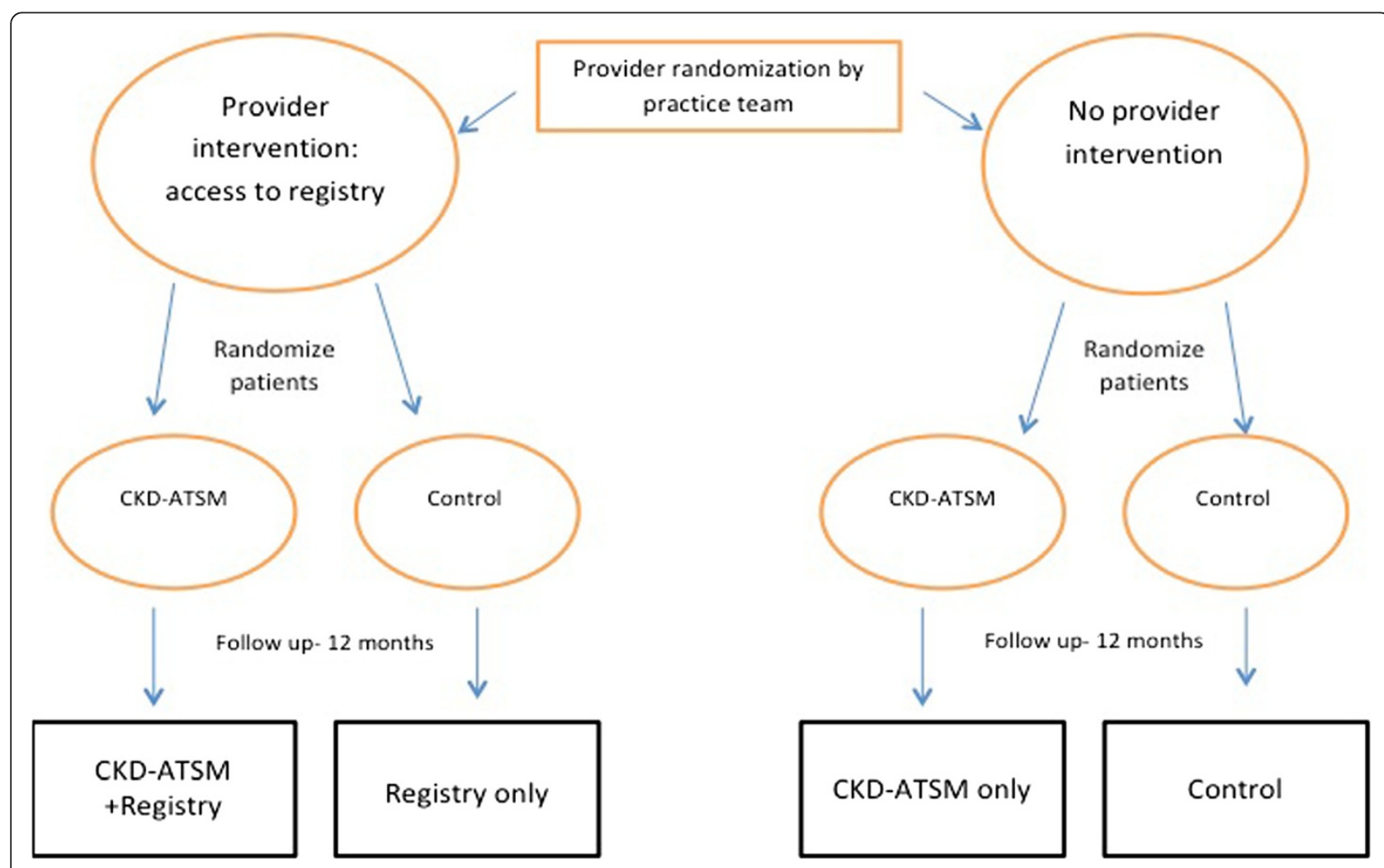

Fig. 2 KARE $2 \times 2$ factorial clinical randomized trial design 
longitudinal primary care to patients, are eligible for this study. Providers who solely provide specialty care, for example HIV services, psychiatric care or urgent care, are excluded from the study.

\section{Patients}

Eligible patients include adults ( $>18$ years) with CKD, defined by an eGFR $15-60 \mathrm{ml} / \mathrm{min} / 1.73 \mathrm{~m}^{2}$ or presence of at least two 1+ dipstick albuminuria separated by at least 90 days. Estimated GFR is calculated using the Modified Diet in Renal Disease study equation [28], as this is automatically reported by the electronic medical record (EMR). Patients must have had contact with their primary health care team at least once within the past 2 years and speak English, Spanish or Cantonese. Kidney transplant recipients, pregnant women, and individuals on dialysis are excluded from this study. Other exclusion criteria include those that impede meaningful communication between providers and patients or limit the usefulness of a CKD self-management support program: prevalent dementia, impaired cognition or severe mental illness; expected life expectancy $<6$ months; self-reported hearing impairment or severe visual impairment preventing use of a touchtone telephone keypad.

\section{Identification and recruitment \\ Providers}

Clinical leadership of primary care clinics in the San Francisco Health Network are approached to participate in this study. All providers from participating clinics are recruited to take part in KARE.

\section{Patients}

The San Francisco Health Network's electronic patient registry is searched to identify eligible study participants. Primary care providers are sent a letter outlining the study objectives with a list of their potentially eligible patients. Providers are asked to identify patients who should be excluded from the study based on the aforementioned exclusion criteria. After receiving provider approval, eligible patients are contacted via telephone to inform them of the study, ensure eligibility, and schedule an enrollment appointment. Voicemails are left for patients who do not respond. For patients who do not respond to 3 phone calls or messages, an attempt is made to call the emergency contact individual listed in the EMR. Successful contact results in an update of the eligible patient's contact information in the EMR and three additional attempts to contact the patient.

\section{Enrollment and randomization Providers}

Consistent with the patient-centered medical home, clinicians in participating primary care clinics are assigned to practice teams responsible for distinct panels of patients. Each team consists of several physicians, nurses, nurse practitioners, medical assistants and behaviorists. Within each clinic, patient demographics across practice teams are similar with respect to race/ethnicity, gender, age and language distribution. To minimize contamination among clinicians, practice teams, rather than primary care providers, are randomized to receive the CKD registry or to receive usual care.

\section{Patients}

Prior to enrollment, using blind and secure allocation by computer, the study team randomly assigns participants to one study arm using a random number generator: CKD-ATSM or usual care. Randomization is blocked and stratified within primary care provider to increase the comparability of treatment groups and to ensure equal allocation by provider. Results are placed in a sealed randomization envelope by a study coordinator.

At the study enrollment appointment, the study team obtains written informed consent and collects baseline study measures. At the completion of this baseline visit, patients learn about their randomization assignment by opening the randomization envelope. Subjects randomized to the intervention arm are provided printed instructions about how to participate in the telephone self-management program and are guided through the process of creating a personalized log-in code for the automated telephone modules. Patients are also given a business card from his/her assigned health coach and a schedule of study events. If randomized to usual care, patients only receive a schedule of study events. All patient participants receive a $\$ 50$ gift card to a local supermarket for their participation in the study.

\section{Interventions}

\section{Provider intervention}

The CKD registry was designed to alert clinicians of a patient's CKD-relevant information and was created with input from San Francisco Health Network clinical leadership and quality improvement champions [29]. This registry, which uses i2iTracks software (http://www.i2isys.com/p/i2itracks), searches the EMR and identifies individuals with CKD based on eGFR and albuminuria, either by dipstick or urinary albumin:creatinine ratio. A printed patient profile provides the primary care practice team with point-of-care data on CKD status, recent blood pressure readings, prescription of pertinent medications (aspirin, ACEi, ARB, statin), recent quantification of albuminuria and recent low-density lipoprotein values, as well as non-CKD specific data that practice teams in the control group receive: immunization status and data pertinent to age appropriate cancer screening. Practice team medical assistants use the patient profile 
while obtaining vital signs during the clinic visit to identify all patients who are not up to date with their age appropriate cancer screening and patients with CKD who need albuminuria quantification and immunizations. The registry also encourages them to notify primary care providers about lapses in guideline-concordant CKD care delivery by highlighting blood pressure readings that are above $140 / 90 \mathrm{mmHg}$ and noting when patients are not on an ACEi or ARB. Written decision support on the patient profile also reminds primary care providers to avoid prescribing non-steroidal anti-inflammatory medications for patients with CKD and to prescribe statin medications when appropriate.

Quarterly written feedback to practice teams focuses on three important groups of patients with CKD: those with uncontrolled BP, those not prescribed an ACEi or $A R B$, and those with persistent macroalbuminuria [14]. Individual PCPs also receive printed sheets identifying their patients who fall in the above categories.

\section{Provider usual care}

Usual care consists of a patient profile that only includes data pertinent to age-appropriate cancer screening. Practice team medical assistants use the patient profile while obtaining vital signs to identify patients who are not up to date with respect to colon cancer, breast cancer and/ or cervical cancer screening.

\section{Patient intervention}

The comprehensive CKD self-management support program consists of three distinct elements that are based on the Social Cognitive Theory constructs of behavioral capability, self-efficacy, expectations and reinforcement [30, 31]: (1) patient educational materials about CKD; (2) automated telephone self-management (CKDATSM); and (3) live telephone-based health coaching. CKD-ATSM was developed with key input from local clinicians to meet the mutli-lingual, low-literacy and diverse cultural needs of the San Francisco safety-net patient population and has been successfully employed in diabetes care [32]. The program consists of 27 different modules that cover topics pertinent to kidney health: basics of kidney disease and its association with hypertension; importance of participation in healthy behaviors (diet, physical activity, smoking cessation, stress reduction); avoidance of non-steroidal anti-inflammatory medications; participation and preparation for clinic visits, complementary medication use; medication adherence; and glycemic control. Offered in English, Spanish, and Cantonese, each phone call has educational messages about 1-2 topics (i.e., nephrotoxic medications), followed by culturally tailored vignettes that highlight selfmanagement behaviors that encourage patients to overcome barriers to engage in their own health and decrease risk of morbidity (i.e., use of Acetaminophen instead of NSAIDS to minimize risk of acute kidney injury). Embedded within these automated phone calls are simple queries that allow the study team to capture data and the health coach to respond to out of range values. The study health coaches receive these data on a weekly basis, allowing them to generate live phone calls to those patients who provide alarming or "out or range" data (i.e., responding "3 or greater" to the question "In the last 7 days, how many days did you miss taking a medication?"). During the live phone calls, health coaches can provide additional education and encourage behavior change through motivational interviewing and action planning. Phone interactions are documented in the EMR, providing seamless integration into medical care (Fig. 3).

The bilingual health coaches employed for this study do not have a medical background. To prepare for the KARE study, they attend $18 \mathrm{~h}$ of training led by the UCSF Center for Excellence in Primary Care (http:// cepc.ucsf.edu/health-coaching). Training is conducted in English, using a curriculum developed by the trainers and study team. Curriculum modules include: working collaboratively with patients; basics of CKD; knowledge of common cardiovascular medications; recognizing "red flags" such as symptoms of depression and not taking any medications; difficulty navigating the clinic; and accessing community resources. Furthermore, coaches are trained to interact with patients using active listening, provide social and emotional support, assist with lifestyle changes and facilitate medication understanding and adherence.

Language-concordant, low-literacy written patient educational materials (PEMs) are given to study participants at baseline and throughout the study period. PEMs were selected after a thorough review of available CKD educational materials [33]. Health coaches refer to these PEMs during their live telephone calls to reinforce concepts and encourage further engagement.

\section{Patient usual care}

Subjects randomized to not receive CKD-ATSM continue to receive medical care at their primary care clinic. They are eligible to receive any of the clinic's usual resources, including interactions with non-physician health care providers, such as nurses, pharmacists, and educators. These resources are also available to study participants randomized to receive CKD-ATSM.

\section{Data collection, follow-up and outcomes Data collection}

In addition to clinical and behavioral outcomes, baseline data are collected to describe the characteristics of study participants (providers and patients) and compare these characteristics between intervention groups assigned by 


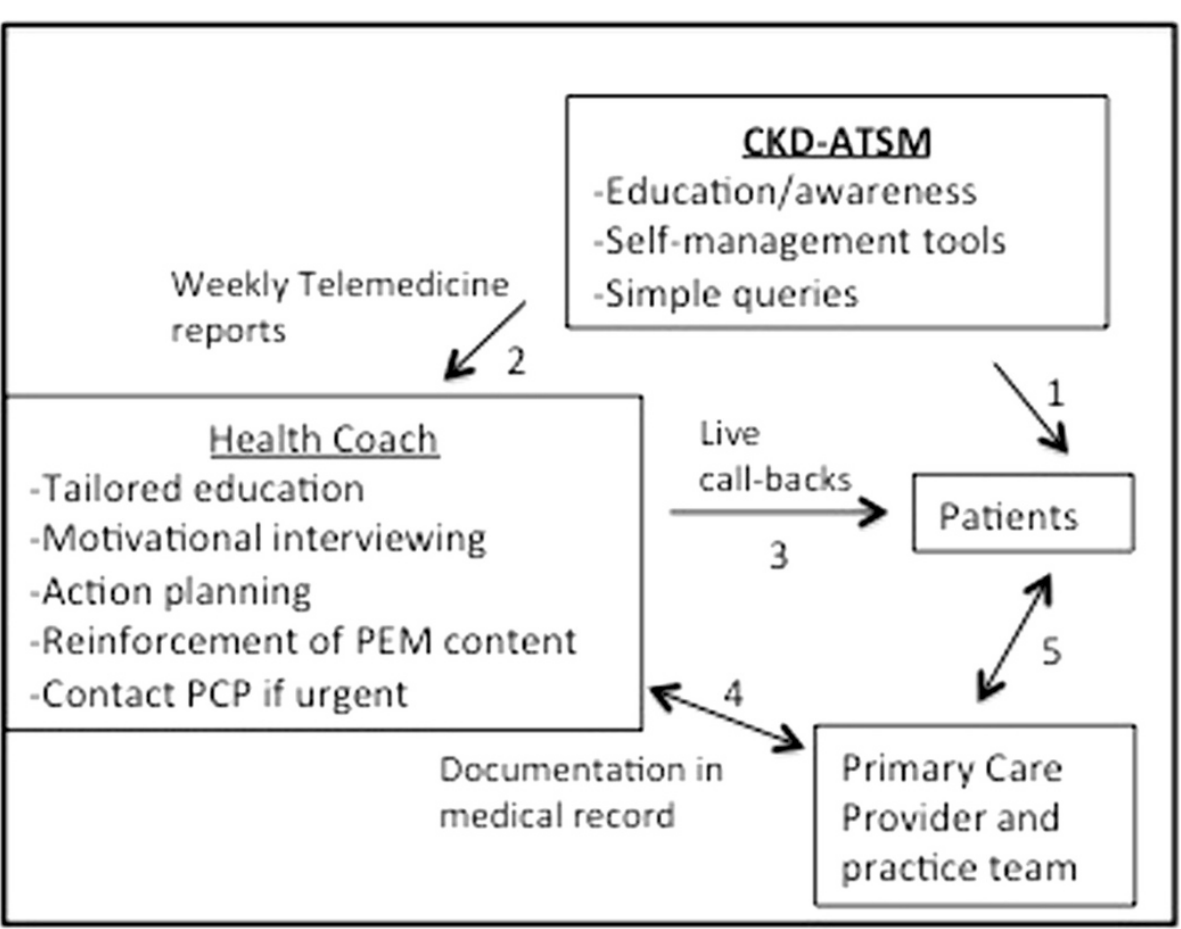

Fig. 3 CKD-ATSM blends health technology with personalized education and counseling

randomization. These data include: self-reported provider demographic data (age, gender, years of experience, specialty, preferred language), provider perception of practice team cohesiveness, self-reported patient sociodemographic data (age, gender, race/ethnicity, social support, education, income, health literacy, zip code, insurance status), co-morbid conditions (diabetes, hypertension, cardiovascular disease), food insecurity, and health literacy (Table 1).

\section{Clinical outcomes}

The primary outcomes are changes in systolic BP and proportion of patients with BP control $(<140 / 90 \mathrm{mmHg})$ after one year. The study team will measure BP using an Omron digital blood pressure monitor model HEM907X during baseline and 12-month study visits. Per study protocol and American Heart Association guidelines, study personnel will obtain 3 BP measures in the right arm after the participant has been sitting quietly for $5 \mathrm{~min}$ [34]. An average of the 3 measures is recorded. Secondary clinical outcomes include: changes in urine albuminuria and weight obtained during by the study team, as well changes in eGFR, laboratory measures of metabolic bone disease (serum calcium, phosphorous, 25-OH Vitamin D and parathyroid hormone) and glycosylated hemoglobin among participants with diabetes, all ascertained through the EMR.

\section{Behavioral outcomes}

Provider and patient behavioral outcomes will inform mechanisms by which the interventions are or are not successful. We will examine changes in provider awareness/identification of CKD, self-efficacy of delivering CKD guideline-concordant care, comfort in provider communication with patients about CKD, prescription of $\mathrm{ACE}$ i or $\mathrm{ARB}$, quantification of albuminuria and nephrology referral. These behavioral data will be ascertained at baseline and at 12 months, using validated instruments when available [35, 36] (Table 1). We will also assess changes in patient awareness of CKD, self-efficacy toward chronic disease self-management, participation in healthy behaviors, medication adherence, and comfort in communicating with providers [37-40] (Table 1).

\section{Process measures}

Many interventions with efficacy ultimately fail because they are not sustained in clinical practice. KARE interventions were designed for integration into clinical care. We will use the Reach, Effectiveness, Adoption, Implementation, and Maintenance (RE-AIM) framework of program evaluation and implementation to evaluate process and feasibility measures [41]. To examine adoption of KARE interventions, we will survey clinicians and primary care clinic staff about integration with clinic 
Table 1 Kidney Awareness Registry and Education (KARE) study variables and outcomes

\begin{tabular}{|c|c|c|c|c|}
\hline KARE Study data collection & Method of ascertainment & Baseline & Mid-point & Study end \\
\hline \multicolumn{5}{|l|}{ Primary care providers } \\
\hline \multicolumn{5}{|l|}{ Demographic data } \\
\hline Age, gender, years of experience, language & Survey & + & & \\
\hline \multicolumn{5}{|l|}{ Behavioral data } \\
\hline Awareness/ability to identify CKD & questionnaire [35] & + & & + \\
\hline Self-efficacy towards CKD management & questionnaire & + & & + \\
\hline $\begin{array}{l}\text { Comfort communicating with patients } \\
\text { about CKD }\end{array}$ & $\begin{array}{l}\text { Communication Assessment } \\
\text { Tool [36] }\end{array}$ & + & & + \\
\hline $\begin{array}{l}\text { Prescription of ACEi or ARB, albuminuria } \\
\text { quantification, nephrology referral }\end{array}$ & Medical record & + & & + \\
\hline \multicolumn{5}{|l|}{ Patients } \\
\hline \multicolumn{5}{|l|}{ Demographic data } \\
\hline $\begin{array}{l}\text { Age, gender, race/ethnicity, social support, } \\
\text { income, education, zip code, preferred } \\
\text { language, insurance status }\end{array}$ & Survey & + & & \\
\hline Food insecurity, health literacy & Screening questions & + & & \\
\hline \multicolumn{5}{|l|}{ Clinical data } \\
\hline BP, Height, Weight, UACR, & Measured by study team & + & & + \\
\hline $\begin{array}{l}\text { eGFR, metabolic bone disease parameters, } \\
\text { glycosylated hemoglobin }\end{array}$ & Medical record & + & & + \\
\hline Co-morbid conditions & Medical record & + & & + \\
\hline $\begin{array}{l}\text { Referrals, emergency department visits, } \\
\text { hospitalizations }\end{array}$ & Medical record & + & & + \\
\hline Current medications & Medical record and study team & + & + & + \\
\hline Quality of life, functional status & SF-12 instrument [37] & + & & + \\
\hline \multicolumn{5}{|l|}{ Behavioral data } \\
\hline CKD awareness & Survey & + & + & + \\
\hline Participation in healthy behaviors & BRFSS questionnaire [40] & + & + & + \\
\hline Self-efficacy for self-management & Stanford self-efficacy tool [39] & + & + & + \\
\hline Medication Adherence & $\begin{array}{l}\text { Morisky Medication Adherence } \\
\text { Scale [38] }\end{array}$ & + & + & + \\
\hline Communication with providers & Lorig Communication tool [39] & + & + & + \\
\hline
\end{tabular}

CKD chronic kidney disease, $A C E i$ angiotensin converting enzyme inhibitor, ARB angiotensin receptor blocker, UACR urine albumin:creaitnine ratio, eGFR estimated glomerular filtration rate, QOL quality of life, BRFSS Behavioral Risk Factor Surveillance System

workflow. We will also assess implementation or fidelity of the self-management program with data from the ATSM information technology platform and audio recordings of health coach conversations. To assess maintenance or sustainability of KARE interventions, we will ask patients about overall satisfaction, comprehension of self-management support, and burden of the intervention during language-concordant focus groups. Provider and practice team satisfaction with the program will be ascertained via survey and focus groups respectively. The resources associated with starting and maintaining each successful intervention will be calculated including personnel time, equipment, and information technology (Table 2).

\section{Sample size considerations}

Sample size and power calculations were performed for the main outcome of interest - change in systolic BP (sBP) after 1 year due to each intervention individually - using effects sizes and standard deviations from multiple published trials of interventions to improve BP control. Baseline data among patients with CKD in the San Francisco Health Network demonstrate an average sBP of $151 \mathrm{mmHg}$ (range: 140-160) across primary care providers, with an intra-class coefficient $=0.0008$. Thus, we used simple $t$-test calculations to determine power analysis. Using a twotailed alpha of 0.05 and beta of 0.8 , we need to enroll 200 patients to each intervention (CKD-ATSM vs. usual care and CKD-registry vs. usual care) to detect a 6-point change 
Table 2 Process outcomes to be studied in the Kidney Awareness Registry and Education (KARE) study

\begin{tabular}{|c|c|c|}
\hline RE-AlM dimension & Outcome & Method of Assessment \\
\hline Adoption & $\begin{array}{l}\text { 1. Are providers and staff satisfied with integration } \\
\text { into clinic work flow? }\end{array}$ & Survey \\
\hline \multirow[t]{3}{*}{ Implementation } & $\begin{array}{l}\text { 1. Are automated telephone recordings delivered } \\
\text { as intended? }\end{array}$ & \multirow{3}{*}{$\begin{array}{l}\text { Data from ATSM information technology platform; } \\
\text { comparison of audio recordings of health coach } \\
\text { conversations vs. CKD-ATSM manual }\end{array}$} \\
\hline & $\begin{array}{l}\text { 2. Is the health coaching intervention delivered } \\
\text { as intended? }\end{array}$ & \\
\hline & $\begin{array}{l}\text { 3. Is health coaching similar across all health } \\
\text { coaches, despite language differences? }\end{array}$ & \\
\hline \multirow[t]{2}{*}{ Maintenance (patient) } & $\begin{array}{l}\text { 1. Are there any difficulties in participating? } \\
\text { Unanticipated issues? }\end{array}$ & \multirow[t]{2}{*}{ Focus groups and questionnaire at study conclusion } \\
\hline & $\begin{array}{l}\text { 2. Are there any unintended consequences of } \\
\text { receiving self-management support? }\end{array}$ & \\
\hline \multirow[t]{3}{*}{ Maintenance (Provider) } & $\begin{array}{l}\text { 1. Do providers read the electronic notes entered } \\
\text { by the health coach? }\end{array}$ & \multirow[t]{3}{*}{ Focus groups and questionnaire at study conclusion } \\
\hline & 2. Do medical assistants use the patient profile routinely? & \\
\hline & $\begin{array}{l}\text { 3. Are there unanticipated consequences of the CKD } \\
\text { registry on delivery of non-CKD chronic disease care? }\end{array}$ & \\
\hline \multirow[t]{2}{*}{ Maintenance } & $\begin{array}{l}\text { 1. Time needed by practice teams to engage with } \\
\text { CKD-registry and perform outreach }\end{array}$ & \multirow[t]{2}{*}{ Health Coach logs, study reports } \\
\hline & $\begin{array}{l}\text { 2. Costs (supplies, time spent by health coaches and } \\
\text { their salaries) for delivery of CKD-ATSM }\end{array}$ & \\
\hline
\end{tabular}

CKD chronic kidney disease, ATSM automated telephone self-management

in systolic BP. This is similar to that achieved by previous team-based intervention trials [42]. Using an interaction analysis, we will also be able to detect a 12-point difference in systolic BP between the arm that receives no intervention and the arm that receives both interventions. To account for a $10 \%$ loss to follow-up, we will need to enroll 220 patients to each intervention, or 110 patients to each arm of the $2 \times 2$ factorial design.

\section{Data analysis}

Evaluation of the individual effectiveness of each intervention, as well as their additive impact, will be performed with intention to treat analyses using generalized estimating equations adjusting for patient age, clinic and preferred language, with robust standard errors to account for clustering by provider and repeated patient measures within provider. If significant differences in baseline characteristics (i.e., age, diabetes status) are found among subjects in each study arm, analyses will be adjusted for these differences using multi-variable linear regression. Additional analyses will look for evidence of effect modification by primary language and CKD severity.

\section{Discussion}

Despite scientific advances that can delay CKD decline and decrease CKD-associated morbidity and mortality, and incorporation of these advances into national [43] and international [44] guidelines, delivery of guideline concordant CKD care remains elusive for many kidney disease patients $[45,46]$. This is particularly true among patients who receive care in safety-net settings, where translation of evidence into practice is often impeded by low patient awareness of CKD, poor patient engagement in care, competing clinical demands, and an inefficient health care delivery system [47].

Patient self-management support is an important component of chronic care management, yet many primary care practices do not consistently provide this support due to limitations of training, time, and resources. Linguistically and culturally concordant health coaches are an untapped resource to provide this support, as demonstrated by a recent study that demonstrated improved BP, glycemic and lipid control among low-income, hypertensive, diabetic or hyperlipidemic patients working with medical assistant health coaches [48]. The KARE study tests the impact of a comprehensive CKD self-management support program that occurs outside of the primary care encounter and employs accessible technology and lay health coaches to enhance patient awareness of CKD and engagement with care.

Supporting providers in their delivery of CKD-care is key to maximizing the clinical benefits of patient health coaching. The KARE study will test the effectiveness of a primary care electronic CKD registry with elements of point-of-care decision support and out-of-care population health, to empower non-physician practice team members to participate in the delivery of guideline concordant care.

We hypothesize that patients who receive ATSM and health coaching, and whose practice teams are randomized to the registry, will show significant improvement 
in systolic BP, reduction in albuminuria, and achieve higher self-efficacy for CKD self-management. If KARE interventions are indeed effective at improving health outcomes among safety-net patients with CKD, the identification of feasible and sustainable characteristics will facilitate their dissemination to other delivery systems across the United States, advancing the goal of healthy equity for people with CKD.

\begin{abstract}
Abbreviations
CKD: Chronic kidney disease; KARE: Kidney Awareness Registry and Education; BP: Blood pressure; ACEi: Angiotensin converting enzyme inhibitor; ARB: Angiotensin receptor blocker; ATSM: Automated telephone self-management; EMR: Electronic medical record; eGFR: Estimated glomerular filtration rate; PEM: Patient educational material.
\end{abstract}

\section{Competing interests}

The authors declare that they have no competing interests.

\section{Authors' contributions}

DST and NRP conceived of study. DST, AV, CEM, TB, YZ, CYH, MH, DS and NRP participated in study design and coordination. DST and AV drafted the manuscript. All authors edited the manuscript and approved the final text.

\section{Funding sources/Support of sponsor}

This work is supported by the R34DK093992 and R01DK104130 from the National Institute of Diabetes and Digestive and Kidney Diseases, Bethesda, MD. Dr. Tuot is supported by K23DK094850 from the National Institute of Diabetes and Digestive and Kidney Diseases as well as the National Center for Advancing Translational Sciences at the National Institutes of Health, through UCSF-CTSI Grant Number UL1TR000004. Drs. Schillinger and Handley are also supported by P30-DK092924 from the National Institute of Diabetes and Digestive and Kidney Diseases.

\section{Author details}

${ }^{1}$ Division of Nephrology, University of California, San Francisco, San Francisco, CA 94143, USA. ${ }^{2}$ Division of General Internal Medicine at San Francisco General Hospital, University of California, San Francisco, San Francisco, CA 94143, USA. ${ }^{3}$ Department of Epidemiology and Biostatistics, University of California, San Francisco, San Francisco, CA 94143, USA. ${ }^{4}$ Center for Vulnerable Populations at San Francisco General Hospital, San Francisco, CA, USA. ${ }^{5}$ Renal Center at San Francisco General Hospital, 1001 Potrero Avenue Bldg 100, Room 342, San Francisco, CA 94110, USA.

Received: 8 June 2015 Accepted: 14 October 2015

\section{Published online: 22 October 2015}

\section{References}

1. Levey AS, Stevens LA, Schmid CH, Zhang YL, Castro 3rd AF, Feldman HI, et al. A new equation to estimate glomerular filtration rate. Ann Intern Med. 2009;150(9):604-12.

2. Go AS, Chertow GM, Fan D, McCulloch CE, Hsu CY. Chronic kidney disease and the risks of death, cardiovascular events, and hospitalization. N Engl J Med. 2004;351(13):1296-305.

3. Merkin SS, Roux AV, Coresh J, Fried LF, Jackson SA, Powe NR. Individual and neighborhood socioeconomic status and progressive chronic kidney disease in an elderly population: the cardiovascular health study. Soc Sci Med. 2007;65(4):809-21.

4. McClellan WM, Newsome BB, McClure LA, Howard G, Volkova N, Audhya P, et al. Poverty and racial disparities in kidney disease: the REGARDS study. Am J Nephrol. 2010;32(1):38-46.

5. Tarver-Carr ME, Powe NR, Eberhardt MS, LaVeist TA, Kington RS, Coresh J, et al. Excess risk of chronic kidney disease among African-American versus white subjects in the United States: a population-based study of potential explanatory factors. J Am Soc Nephrol. 2002;13(9):2363-70.

6. Hall YN, Choi Al, Chertow GM, Bindman AB. Chronic kidney disease in the urban poor. Clin J Am Soc Nephrol. 2010;5(5):828-35.
7. Hall YN, Rodriguez RA, Boyko EJ, Chertow GM, O'Hare AM. Characteristics of uninsured Americans with chronic kidney disease. J Gen Intern Med. 2009;24(8):917-22.

8. Tight blood pressure control and risk of macrovascular and microvascular complications in type 2 diabetes: UKPDS 38. UK Prospective Diabetes Study Group. BMJ 1998, 317(7160):703-713.

9. Brenner BM, Cooper ME, de Zeeuw D, Keane WF, Mitch WE, Parving HH, et al. Effects of losartan on renal and cardiovascular outcomes in patients with type 2 diabetes and nephropathy. N Engl J Med. 2001;345(12):861-9.

10. Lewis EJ, Hunsicker LG, Clarke WR, Berl T, Pohl MA, Lewis JB, et al. Renoprotective effect of the angiotensin-receptor antagonist irbesartan in patients with nephropathy due to type 2 diabetes. N Engl J Med. 2001;345(12):851-60.

11. Randomised placebo-controlled trial of effect of ramipril on decline in glomerular filtration rate and risk of terminal renal failure in proteinuric, non-diabetic nephropathy. The GISEN Group (Gruppo Italiano di Studi Epidemiologici in Nefrologia). Lancet 1997, 349(9069):1857-1863.

12. The effect of intensive treatment of diabetes on the development and progression of long-term complications in insulin-dependent diabetes mellitus. The Diabetes Control and Complications Trial Research Group. N Engl J Med 1993, 329(14):977-986.

13. Intensive blood-glucose control with sulphonylureas or insulin compared with conventional treatment and risk of complications in patients with type 2 diabetes (UKPDS 33). UK Prospective Diabetes Study (UKPDS) Group. Lancet 1998, 352(9131):837-853.

14. KDIGO. Clinical practice guideline for the evaluation and management of chronic kidney disease. Summary of recommendation statements. Kidney Int Suppl 2013. 2012;3(1):5-14.

15. Plantinga LC, Tuot DS, Powe NR. Awareness of chronic kidney disease among patients and providers. Adv Chronic Kidney Dis. 2010;17(3):225-36.

16. Tuot D, Plantinga L, Judd S, Muntner P, Hsu C, Warnock DG, et al.. Health behaviors, risk factor control and awareness of chronic kidney disease. Am J Nephrol. In press. 2013.

17. Tuot DS, Plantinga LC, Hsu CY, Jordan R, Burrows NR, Hedgeman E, et al. Chronic kidney disease awareness among individuals with clinical markers of kidney dysfunction. Clin J Am Soc Nephrol. 2011;6(8):1838-44.

18. Tahir MA, Dmitrieva O, de Lusignan S, van Vlymen J, Chan T, Golmohamad $R$, et al. Confidence and quality in managing CKD compared with other cardiovascular diseases and diabetes mellitus: a linked study of questionnaire and routine primary care data. BMC Fam Pract. 2011;12:83.

19. Costantini L, Beanlands H, McCay E, Cattran D, Hladunewich M, Francis D. The self-management experience of people with mild to moderate chronic kidney disease. Nephrol Nurs J. 2008;35(2):147-55. quiz 156.

20. Bodenheimer T, Lorig K, Holman H, Grumbach K. Patient self-management of chronic disease in primary care. JAMA. 2002;288(19):2469-75.

21. Wagner EH, Austin BT, Davis C, Hindmarsh M, Schaefer J, Bonomi A. Improving chronic illness care: translating evidence into action. Health Aff (Millwood). 2001;20(6):64-78.

22. American College of Physicians. The Patient-Centered Medical Home Neighbod: The Interface of the Patient Centered Medical Home With Specialty/Subspecialty Practices. Philadelphia, PA: American College of Physicians; 2010.

23. Rich MW, Beckham V, Wittenberg C, Leven CL, Freedland KE, Carney RM. A multidisciplinary intervention to prevent the readmission of elderly patients with congestive heart failure. N Engl J Med. 1995;333(18):1190-5.

24. Bodenheimer T, Wagner EH, Grumbach K. Improving primary care for patients with chronic illness: the chronic care model, Part 2. JAMA. 2002;288(15):1909-14.

25. Halladay JR, Dewalt DA, Wise A, Qaqish B, Reiter K, Lee SY, et al. More extensive implementation of the chronic care model is associated with better lipid control in diabetes. J Am Board Fam Med. 2014;27(1):34-41.

26. Volkova N, McClellan W, Klein M, Flanders D, Kleinbaum D, Soucie JM, et al. Neighborhood poverty and racial differences in ESRD incidence. J Am Soc Nephrol. 2008;19(2):356-64.

27. Schillinger D. Literacy and health communication: reversing the 'inverse care law'. Am J Bioeth. 2007;7(11):15-8. discussion W11-12.

28. Levey AS, Bosch JP, Lewis JB, Greene T, Rogers N, Roth D. A more accurate method to estimate glomerular filtration rate from serum creatinine: a new prediction equation. Modification of diet in renal disease study group. Ann Intern Med. 1999;130(6):461-70.

29. McBride D, Dohan D, Handley MA, Powe NR, Tuot DS. Developing a CKD registry in primary care: provider attitudes and input. Am J Kidney Dis. 2013. 
30. Painter JE, Borba CP, Hynes M, Mays D, Glanz K. The use of theory in health behavior research from 2000 to 2005: a systematic review. Ann Behav Med. 2008;35(3):358-62.

31. Glanz K, Rimer BK, Viswanath K. Health behavior and health education : theory, research, and practice. 4th ed. San Francisco, CA: Jossey-Bass; 2008.

32. Schillinger $\mathrm{D}$, Handley M, Wang $\mathrm{F}$, Hammer $\mathrm{H}$. Effects of self-management support on structure, process, and outcomes among vulnerable patients with diabetes: a three-arm practical clinical trial. Diabetes Care. 2009;32(4):559-66.

33. Tuot DS, Davis E, Velasquez A, Banerjee T, Powe NR. Assessment of printed patient-educational materials for chronic kidney disease. Am J Nephrol. 2013;38(3):184-94.

34. Pickering TG, Hall JE, Appel LJ, Falkner BE, Graves J, Hill MN, et al. Recommendations for blood pressure measurement in humans and experimental animals: part 1: blood pressure measurement in humans: a statement for professionals from the subcommittee of professional and public education of the american heart association council on high blood pressure research. Circulation. 2005;111(5):697-716.

35. Boulware LE, Troll MU, Jaar BG, Myers DI, Powe NR. Identification and referral of patients with progressive CKD: a national study. Am J Kidney Dis. 2006;48(2):192-204.

36. Campbell C, Lockyer J, Laidlaw T, Macleod H. Assessment of a matched-pair instrument to examine doctor-patient communication skills in practising doctors. Med Educ. 2007:41(2):123-9.

37. Ware Jr J, Kosinski M, Keller SD. A 12-item short-form health survey: construction of scales and preliminary tests of reliability and validity. Med Care. 1996;34(3):220-33.

38. Morisky DE, Green LW, Levine DM. Concurrent and predictive validity of a self-reported measure of medication adherence. Med Care. 1986;24(1):67-74.

39. Lorig K, Stewart AF, Ritter P, Gonzalez V, Laurent D, Lynch J. Outcome Measures for Health Education and Other Health Care Intervensions. Thousand Oaks, CA: Sage Publications; 1996.

40. Behavioral Risk Factor Surveillance System Survey Questionnaire. In. Atlanta, Ceorgia: The U.S. Department of Health and Human Services, Centers for Disease Control and Prevention (CDC); 2011.

41. Glasgow RE, Nelson CC, Strycker LA, King DK. Using RE-AIM metrics to evaluate diabetes self-management support interventions. Am J Prev Med. 2006:30(1):67-73.

42. Carter BL, Rogers M, Daly J, Zheng S, James PA. The potency of team-based care interventions for hypertension: a meta-analysis. Arch Intern Med. 2009;169(19):1748-55.

43. Inker LA, Astor BC, Fox CH, Isakova T, Lash JP, Peralta CA, et al. KDOQI US commentary on the 2012 KDIGO clinical practice quideline for the evaluation and management of CKD. Am J Kidney Dis. 2014;63(5):713-35.

44. KDIGO. Clinical practice guideline for the evaluation and management of chronic kidney disease. Kidney Int. 2012;2013:3(1).

45. Tuot DS, Plantinga LC, Hsu CY, Powe NR. Is awareness of chronic kidney disease associated with evidence-based guideline-concordant outcomes? Am J Nephrol. 2012;35(2):191-7.

46. Tuot DS, Powe NR. Chronic kidney disease in primary care: an opportunity for generalists. J Gen Intern Med. 2011;26(4):356-8.

47. Tuot DS, Grubbs V. Chronic kidney disease care in the US safety Net. Adv Chronic Kidney Dis. 2015;22(1):66-73.

48. Willard-Grace R, Chen EH, Hessler D, DeVore D, Prado C, Bodenheimer T, et al. Health coaching by medical assistants to improve control of diabetes, hypertension, and hyperlipidemia in low-income patients: a randomized controlled trial. Ann Fam Med. 2015;13(2):130-8.

\section{Submit your next manuscript to BioMed Central and take full advantage of:}

- Convenient online submission

- Thorough peer review

- No space constraints or color figure charges

- Immediate publication on acceptance

- Inclusion in PubMed, CAS, Scopus and Google Scholar

- Research which is freely available for redistribution 